http://dx.doi.org/10.18778/0208-6107.32.03

\author{
Pranab Rudra \\ Institute of the History, \\ Philosophy and Ethics of Medicine \\ Ulm University \\ pranab-1.rudra@uni-ulm.de
}

\title{
ETHICAL UNDERPINNING AND IMPLICATIONS OF "NOOTROPIC" CONCEPT
}

\begin{abstract}
The current generation paving the path for new research marks a milestone to attain the ancient goal of improving our cognition. To date, increased prevalence of cognitive enhancers by healthy people has raised the scientific community's attention as well as media coverage. In particular, nootropics such as piracetam promise to offer modest improvements in cognitive performance. The long-lasting impetus of this "holistic enhancer" convinced scientists as well as ethicists to discuss its potential ethical implications and future directions. Moreover, there are discrepancies in the concept of a true nootropic between pharmacology and contemporary public culture. Here, I review the ethical aspects of nootropics raised by its potential use in cognition enhancement and substantiate the epistemological commentary on the concept of nootropic.
\end{abstract}

\section{Keywords:}

Nootropic drugs, nootropic concept, neurocognitive enhancement, ethics

\section{INTRODUCTION}

Since ancient times, drugs to enhance cognition have had an irresistible universal appeal when they not only target the disease but any possible subjective symptoms that are more or less present in any healthy being. Students in ancient Greece used rosemary sprigs to improve their memory. Now shelves on drug stores carry all the necessary pills and tonics to purportedly enhance cognition. ${ }^{1}$ Between ancient societies and modern times, the use of nootropic substances accelerated during the post-war period (1950-1960s) where it

\footnotetext{
${ }^{1}$ Richard Le Strange, A History of Herbal Plants (London: Angus \& Robertson Publ., 1977).
} 
became increasingly commercialized. An escalation of "cosmetic neurology" in western and non-western societies has caught the attention of the scientific community as well as that of the media. The aim is not only to augment the minds of the unhealthy but also the minds of the healthy. ${ }^{2}$ Prescription stimulants were originally intended and licensed for the treatment of specific cognitive disorders (e.g. Alzheimer's disease or Attention Deficit Hyperactivity Disorder). Now, they are diverted to healthy individuals for enhancement purposes. This is resulting in a divisible issue both from the perspective of scientists as well as the public sector. ${ }^{3}$ The use of nootropics for military and non-military purposes and off-label use among college students initiated furious discussions among scientists, ethicists, physicians, and government. Arguments on the topic include unfair advantage, indirect coercion, side-effects or harm, and ethical implications. The goal is to tackle the issue and to make policies for future nootropic regulation due to its effect to alter the human mind - a highly valued part of our human existence. ${ }^{4}$ While discussions of this issue will become more pressing in years to come, the issues become even cloudier and more confusing when the 'pure' definition of nootropic and its ethical implications

\footnotetext{
${ }^{2}$ Anjan Chatterjee, "The Promise And Predicament of Cosmetic Neurology," Journal of Medical Ethics 32, no. 2 (2006): 110-113, doi:10.1136/jme.2005.013599; Anjan Chatterjee, "Cosmetic Neurology: The Controversy over Enhancing Movement, Mentation, and Mood," Neurology 63, no. 6 (2004): 968-974, doi:10.1212/01.wnl.0000138438.88589.7c.

${ }^{3}$ Martha J. Farah et al., "Neurocognitive Enhancement: What Can We Do and What Should We Do?," Nature Reviews Neuroscience 5, no. 5 (2004); Eric Racine and Cynthia Forlini, "Cognitive Enhancement, Lifestyle Choice or Misuse of Prescription Drugs?" Neuroethics 3, no. 1 (2008): 1-4, doi:10.1007/s12152-008-9023-7; Henry Greely et al., "Towards Responsible Use of CognitiveEnhancing Drugs By The Healthy," Nature 456, no. 7223 (2008): 702-705, doi:10.1038/456702a; Francis Fukuyama, Our Posthuman Future: Consequences of the Biotechnology Revolution (New York: Picador, 2003); Vince Cakic, "Smart Drugs for Cognitive Enhancement: Ethical and Pragmatic Considerations in the Era of Cosmetic Neurology," Journal of Medical Ethics 35, no. 10 (2009): 611-615, doi:10.1136/jme.2009.030882; Danielle C. Turner et al., "Cognitive Enhancing Effects of Modafinil in Healthy Volunteers," Psychopharmacology 165, no. 3 (2003): 260-269, doi:10.1007/s00213-002-1250-8; Sean Esteban McCabe et al., "Non-Medical Use of Prescription Stimulants Among US College Students: Prevalence and Correlates from a National Survey," Addiction 100, no. 1 (2005): 96-106, doi:10.1111/j.1360-0443.2005.00944.x.

${ }^{4}$ Quinton Babcock and Tom Byrne, "Student Perceptions of Methylphenidate Abuse at a Public Liberal Arts College," Journal of American College Health 49, no. 3 (2000): 143-145, doi:10.1080/07448480009596296; Farah et al., "Neurocognitive Enhancement: What Can We Do And What Should We Do?"; Amy F. T. Arnsten and Anne G Dudley, "Methylphenidate Improves Prefrontal Cortical Cognitive Function Through A2 Adrenoceptor and Dopamine D1 Receptor Actions: Relevance to Therapeutic Effects in Attention Deficit Hyperactivity Disorder," Behavioral and Brain Functions 1, no. 1 (2005): 2, doi:10.1186/1744-9081-1-2; Danielle C. Turner et al., "Cognitive Enhancing Effects of Modafinil in Healthy Volunteers," Psychopharmacology 165, no. 3 (2003): 260-269, doi:10.1007/s00213-002-1250-8; Nick Bostrom and Anders Sandberg, "Cognitive Enhancement: Methods, Ethics, Regulatory Challenges," Science and Engineering Ethics 15, no. 3 (2009): 311-341, doi:10.1007/s11948-009-9142-5.
} 
come into play. The definition dating back to the work of the Romanian-Belgian physician and neuropharmacist Corneliu E. Giurgea (1923-1997), who coined the term nootropic, and the salient ethical concerns raised by the use of nootropic will be discussed in details here.

\section{THE NOOTROPIC CONCEPT}

In the 1960s, gamma-amino-butyric acid (GABA) was stirring high scientific interest as a major inhibitory neurotransmitter in the brain. In 1964, chemists in Union Chimique Belge (UCB) synthesized a cyclic derivate of GABA, the piracetam, intended for use as a sleep inducer. Surprisingly, piracetam did not show any type of sleep-inducing activity. This peculiar effect of the prominent neurotransmitter accidentally caught the attention of Corneliu E. Giurgea who was UCB's chief neuropharmacologist at that time. In 1972, the unique properties of piracetam led Giurgea to introduce the novel concept of "nootropic drugs" that "characteristically interfere with the higher telencephalic integrative activity by a direct and selective attention."

According to Giurgea and Salama, the detailed definition of nootropic should have the following properties: 1) enhance memory and ability to learn, 2) increase the efficacy of neuronal firing (controls mechanism in cortical and subcortical region of the brain), 3) help brain function (e.g. under hypoxic conditions), 4) protect the brain (chemical or physical assault), and 5) be virtually non-toxic to humans (lacks sedative or stimulatory effects). ${ }^{6}$ This atypical pharmacological concept suggests no drug-receptor interaction, hence no modulatory effect, and very weak affinity due to its extremely low toxicity. ${ }^{7}$ Although piracetam has been reported to having cholinergic, serotoninergic, noradrenergic, and glutamatergic effects, there is no direct agonistic or antagonistic receptor showing a noticeable affinity, unlike any psychotropic drugs on the market.

Soon the mass media and professionals nicknamed nootropics as "smart drugs" and "cognitive enhancers" respectively due to its uncommon lack of toxicity and reported memory enhancement among healthy college students (see Figure 1$).{ }^{8}$ It is important to note that any nootropic defined by Giurgea would

\footnotetext{
${ }^{5}$ C. Giurgea and M. Salama, "Nootropic Drugs," Progress in Neuro-Psychopharmacology 1, no. 3-4 (1977): 235-247, doi:10.1016/0364-7722(77)90046-7.

${ }^{6}$ Ibid.

${ }^{7}$ Bengt Winblad, "Piracetam: A Review of Pharmacological Properties and Clinical Uses," CNS Drug Reviews 11, no. 2 (2006): 169-182, doi:10.1111/j.1527-3458.2005.tb00268.x.

${ }^{8}$ Stuart J. Dimond and E. Y. M. Brouwers, "Increase in the Power Of Human Memory in Normal Man Through the Use of Drugs," Psychopharmacology 49, no. 3 (1976): 307-309,
} 
be a cognitive enhancer or smart drug, but the opposite is not true, since drugs are not devoid of toxicity. Unlike smart drugs or cognitive enhancers, nootropic drugs do not enhance alertness, arousal, locomotion, heart rate, or blood pressure. Furthermore, when administered for the first time, there are no observable effects in the patient who takes it. Only after around two weeks of consistent administration, statistically significant effects are observable in the patient. ${ }^{9}$ Therefore, the effects of the nootropic piracetam warranted a solely noetic class of smart drugs or cognitive enhancers that is without side effects, toxicity and is non-immediate.

All these properties clearly indicate a holistic concept of nootropic drugs, natural or synthetic, as opposed to a pharmacological agonist-antagonist mechanism. Naturally, nootropic drugs do not target any single type of neuron. Rather, they are meant to activate the integrative activities of the brain. As Aristotle explains holistic phenomena with the phrase "The whole is more than the sum of its parts," Giurgea further adds to this phenomenon as neuro-psychic identity where human brain activity is but complex aspects of a neuronal activity easier to grasp at an elementary level. ${ }^{10}$ This illustrates the bewildering complexity of brain and mind both from the perspective of René Descartes's (1596-1650) mind-body dichotomy and Freudian psychoanalysis.

Understandably, the promising success of nootropic drugs inadvertently catalyzed the paradigm of a new and undiscovered avenue of research for the future of enhancement. Thirty years after the 'birth' of piracetam, more than 1650 piracetam-like compounds were synthesized. ${ }^{11}$ The progeny of piracetam, namely levetiracetam and brivaracetam, showed promising results as antiepileptic drugs that are far more efficient than piracetam. ${ }^{12}$ Therefore, one can conclude that the nootropic piracetam acted as a template of the new piracetamlike drugs that - while no longer holding true nootropic definition - treat severe neurological diseases with increasing medical demands.

doi:10.1007/bf00426834; Doru Georg Margineanu, “A Weird Concept with Unusual Fate: Nootropic Drug," Revue des Questions Scientifiques 182, no. 1 (2011): 33-52.

${ }^{9}$ Dimond and Brouwers, "Increase in the Power of Human Memory in Normal Man Through the Use of Drugs."

${ }^{10}$ Margineanu, "A Weird Concept with Unusual Fate: Nootropic Drug."

11 Alex Haahr Gouliaev and Alexander Senning, "Piracetam and Other Structurally Related Nootropics," Brain Research Reviews 19, no. 2 (1994): 180-222, doi:10.1016/01650173(94)90011-6.

12 Tim De Smedt et al., "Levetiracetam: Part II, The Clinical Profile of a Novel Anticonvulsant Drug," CNS Drug Reviews 13, no. 1 (2007): 57-78, doi:10.1111/j.1527-3458.2007.00005.x; Jacqueline A. French et al., "Adjunctive Brivaracetam for Refractory Partial-Onset Seizures: A Randomized, Controlled Trial," Neurology 75, no. 6 (2010): 519-525, doi:10.1212/wnl.0b013e3181ec7f7f. 


\section{Primary stage of pioneering nootropics}

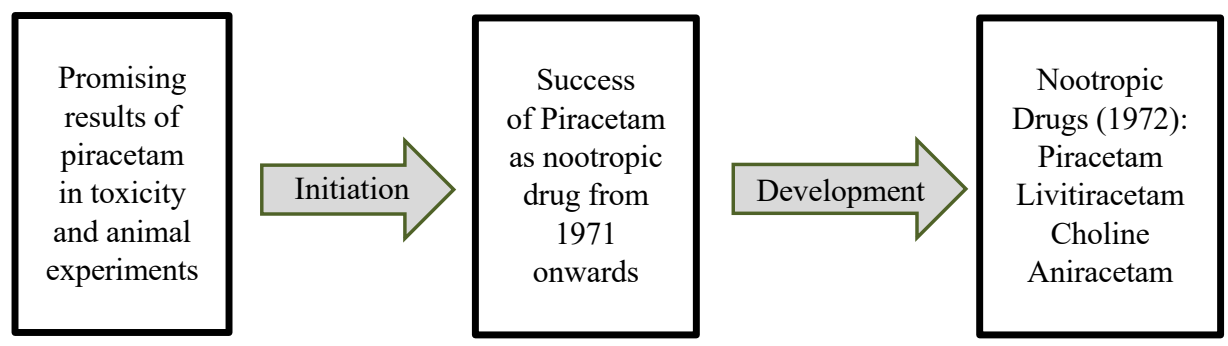

\section{Secondary stage of nootropics commercialization}

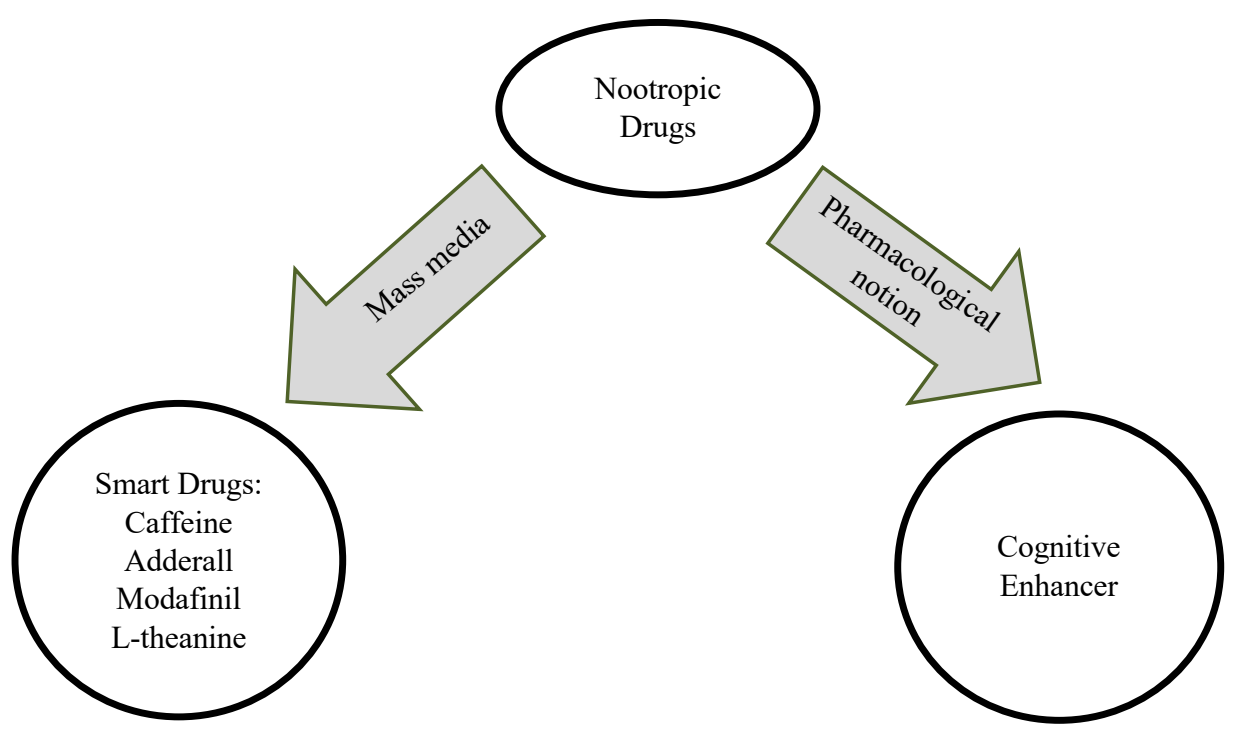

Figure 1. Schematic diagram of the unfolding of the 'nootropic' drug concept. The term nootropic evolved from the unique properties of piracetam and that promoted success of further nootropic drugs. The term 'smart drug' and 'cognitive enhancer' are commonly used in mass media and in professional pharmacological field respectively (adapted from Margineanu 2011). 


\section{METHODOLOGY}

A search of "nootropic" done in US National Library of Medicine (PubMed; https://www.ncbi.nlm.nih.gov/pubmed) on 1st July 2018 indicated a list of 5392 references, illustrated an exponential increase over the years starting with the paper of Giurgea from 1972 (see Figure 2). The search term "nootropic" was sorted by most recent without any filters of article types, text availability, publication dates and species added to it. The PubMed database also has the possibility to download results per year as .csv file to work in Microsoft Excel. Based on the excel sheet data, I was able to plot a histogram on Microsoft Excel 2016 as shown in Figure 2.

Moreover, the article investigates some of the most popular ethical theories that can be associated to nootropics, particularly consequentialism versus deontology, four principles in medical ethics and virtue ethics. Furthermore, discussions on how we perceive the trade-off between potential benefits and harms, how enhancers can affect students and athletes and open ethical questions are also addressed.

\section{RESULTS AND ETHICAL DISCUSSIONS}

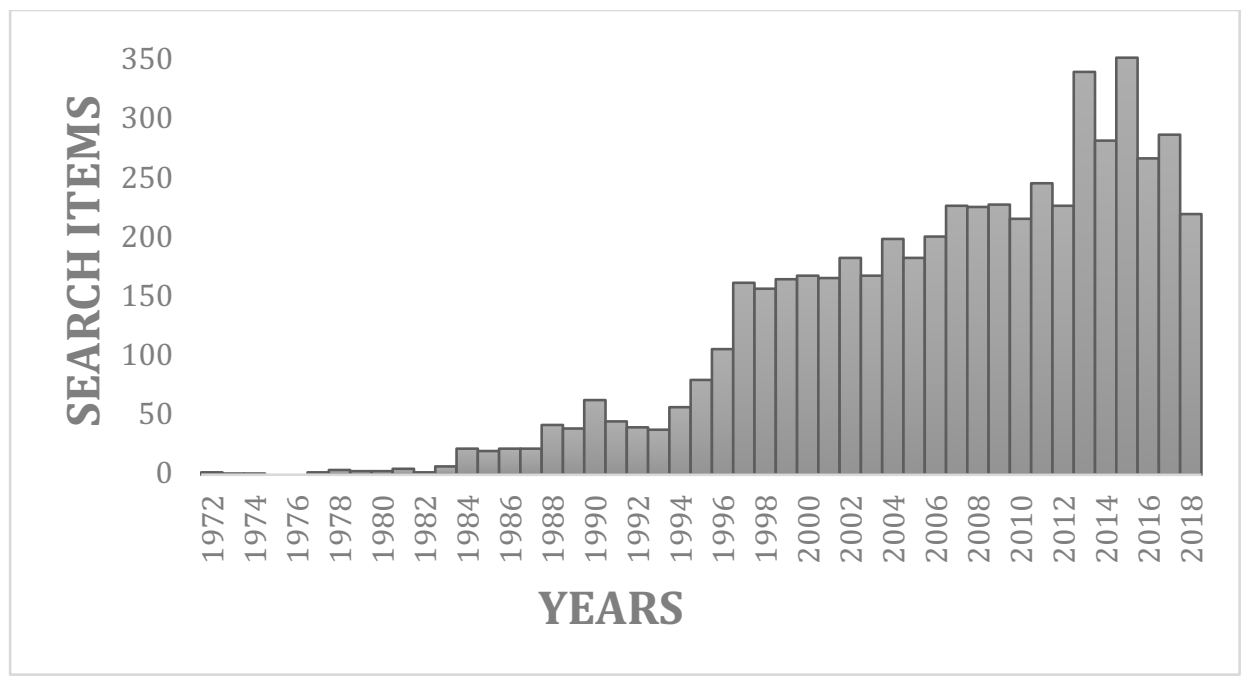

Figure 2. The long-lasting interest in nootropic showed an exponential evolution in time of the number of scientific publications in the PubMed database, accessed on $1^{\text {st }}$ July 2018. Above each column the number indicates the total number of published articles per year. 
Open ethical questions

In light of nootropic drugs, an integral part of the ethical controversy lies in understanding the question - who is the patient? In order to use nootropics, should the individual be ill with mental illness or other disorders or should nootropics also be prescribed to individuals who are healthy? Considering preventive care, all individuals must qualify for medical care and must have an improved quality of life. If that is the case, how does one differentiate nootropics between a prescription drug and a lifestyle choice? Scientists, ethicists, and physicians have divergent opinions on these questions and operate on separate paradigms. In academia, Greely et al. advocates the use of cognitive enhancers, provided it is properly regulated, while Chatterjee and Fukuyama are against cognitive enhancement. ${ }^{13}$ In the book Our Posthuman Future, Fukuyama clearly argues that "the original purpose of medicine is to heal the sick, not turn healthy people into gods. ${ }^{14}$ Such discrepancies warrant unified policy decisions regulating the proper use of cognitive enhancement, particularly nootropic of any source (i.e., supplements, herbal extracts and allopathic).

\section{Risk-benefit ratio}

Another aspect of ethical concern is the risk-benefit ratio of nootropic drugs. When a physician prescribes the drug, the physician must assess the desired benefits and the risks involved. Generally, patients choose drugs with greater benefits even though serious risks are associated with them. This is particularly the case for nootropic drugs since the benefits of cognitive enhancement are very lucrative and tolerance for risks is severely lowered among healthy individuals. ${ }^{15}$ As suggested by Greely et al., it is important for both patient and doctor to make a fully informed decision to minimize risk and achieve greater benefits. ${ }^{16}$ However, Chatterjee argues that no potential risks for healthy individuals are to be tolerated. ${ }^{17}$ Respect for autonomy as well as the fulfillment of

\footnotetext{
${ }^{13}$ Greely et al., "Towards Responsible Use of Cognitive-Enhancing Drugs by the Healthy," Nature 456, no. 7223 (2008): 702-705, doi:10.1038/456702a; Farah et al., "Neurocognitive Enhancement: What Can We Do and What Should We Do?"; John Harris, "Is It Acceptable for People to Take Methylphenidate to Enhance Performance? Yes," BMJ 338, no. 182 (2009): b1955, doi:10.1136/bmj.b1955; Fukuyama, Our Posthuman Future; Anjan Chatterjee, "Is It Acceptable For People to Take Methylphenidate to Enhance Performance? No," BMJ 338, no. 182 (2009): b1956, doi:10.1136/bmj.b1956.

${ }^{14}$ Fukuyama, Our Posthuman Future, 208.

${ }^{15}$ Farah et al., "Neurocognitive Enhancement: What Can We Do and What Should We Do?"; Cakic, "Smart Drugs for Cognitive Enhancement: Ethical and Pragmatic Considerations in the Era Of Cosmetic Neurology"; James Butcher, "Cognitive Enhancement Raises Ethical Concerns," The Lancet 362, no. 9378 (2003): 132-133, doi:10.1016/s0140-6736(03)13897-4.

${ }^{16}$ Greely et al., "Towards Responsible Use of Cognitive-Enhancing Drugs by the Healthy."

${ }^{17}$ Chatterjee, "Cosmetic Neurology: The Controversy over Enhancing Movement, Mentation, and Mood"; Chatterjee, "The Promise and Predicament of Cosmetic Neurology."
} 
patient's wishes may not medically justify exposing a patient to risk for severe adverse reactions or any form of possible side-effects. In any case, proper communication should be facilitated between patient and physician for optimal regulation of nootropic drugs. More importantly, the scientists should ensure that the results of their clinical research are portrayed accurately and that they are employed to aid ethical decisions.

\section{Nootropics in practical settings}

Disparities exist in the use of nootropics between the academic setting and sports, creating an uneven field where one can outperform the other. Similarly, the wealthy might have greater opportunity to obtain nootropic drugs, thus creating a monopoly in the market and incongruities between socioeconomic classes. One can argue about naturally endowed higher hereditary IQ and performance-enhancing strategies like private tuition in the academic field which are readily tolerated by society. It would seem hypocritical to be selective primarily on nootropics and not on biological and environmental inequalities that already exist. ${ }^{18}$ It is interesting to consider whether there would be a possibility to make nootropics accessible to the underprivileged, i.e., people with cognitive deficits or individuals with deleterious effects. Students who are considered as 'neurologically handicapped' could benefit from nootropic use by increasing academic performance.

One keystone that ethicists are often critical about is the perception of the self. Nootropics raise argument because they seem to unsettle an integral part of our humanity, thus causing individuals to be at risk. ${ }^{19}$ The natural act of human suffering or striving towards a destined goal could be bypassed using nootropics, thus altering the definition of self. ${ }^{20}$ Wolpe mentions the genuine struggle to learn something is an individual's personhood. Naturally, one can argue that today's dynamically changing technology allow us to redevelop our own identities and nootropic can help reintegrate us into the modern race.

\section{Consequentialism versus deontology}

From a broader perspective, consequentialism reflects on right or wrong depending on the consequences that can be evaluated in different ways. According to Swierstra and Rip, the consequences of cognitive enhancers such

\footnotetext{
${ }^{18}$ Martha J. Farah, "Emerging Ethical Issues in Neuroscience," Nature Neuroscience 5, no. 11 (2002): 1123-1129, doi:10.1038/nn1102-1123; Bengt Kayser, Alexandre Mauron and Andy Miah, "Current Anti-Doping Policy: A Critical Appraisal," BMC Medical Ethics 8, no. 1 (2007), doi:10.1186/1472-6939-8-2.

${ }^{19}$ Butcher, "Cognitive Enhancement Raises Ethical Concerns"; Chatterjee, "Cosmetic Neurology: The Controversy over Enhancing Movement, Mentation, and Mood"; Paul Root Wolpe, "Treatment, Enhancement, and the Ethics of Neurotherapeutics," Brain and Cognition 50, no. 3 (2002): 387-395, doi:10.1016/s0278-2626(02)00534-1.

${ }^{20}$ Ibid.
} 
as nootropics are still speculative and remain undetermined, which points to "promises, warnings and concerns." ${ }^{21}$ Having an optimistic view about nootropics, one can assume that any cognitive enhancer, say in this case piracetam, is basically beneficial for everyone, and not limited to people with a diagnosis but also for healthy alike. However, Rip and Swierstra mention "optimistic belief in technological progress short-circuits the problem of uncertainty and ignorance by arguing that there may be small mishaps, but all in all, and in the long run, the new technology will benefit us." 22 Just like an optimistic viewpoint, it is important to note that pessimistic perspectives short-circuit the question of risk and uncertainty of cognitive enhancers since "you may not know exactly what will go wrong, but go wrong it will." 23

In contrast, deontology determines the intention and reason for performing an action rather than the end result or consequences of that particular action. If an action is undertaken out of a sense of moral obligation rather than just sentiment or consequential reasons, then that action is considered morally praiseworthy. The course of action of the moral agent through rational deliberation is consistent with the agent's autonomy and others. In the following, the deontological argumentation will be characterized as duty and right based argumentation that will bring light to frame arguments in favor or against cognitive enhancement. According to Swierstra and Rip, deontology is characterized as the "duty to further human progress, a duty to help diminish suffering, a duty to acquire knowledge, and last but certainly not least: the right to choose freely whether or not to use a particular technology (as long as this does not harm others, of course)." ${ }^{24}$ An underlying determinist idea to support development in cognitive enhancement: "the argument about [...] technology as an unstoppable train, because 'if we don't do it, our competitors will'. [...] The optimism gains extra 'muscle' by combining it with determinism." 25 Portraying a continuum from a cognitive enhancing pill to a chip in the brain, moral argumentation reflects consequentialism aspects as "technology, although seemingly innocuous or even beneficial now, will inevitably invoke further technological steps that will later result in applications that are blatantly immoral." ${ }^{26}$ The deontological side of such an argument would be the common responsibility and necessity to reflect on our cognitive capacities rather than inabilities, in particular what we can do without nootropics.

\footnotetext{
21 Tsjalling Swierstra and Arie Rip, "Nano-Ethics as NEST-Ethics: Patterns of Moral Argumentation about New and Emerging Science and Technology," Nanoethics 1, no. 1 (2007): 3-20, doi:10.1007/s11569-007-0005-8.

${ }^{22}$ Ibid., 11.

${ }^{23}$ Ibid.

${ }^{24}$ Ibid., 14.

${ }^{25}$ Ibid., $11,14$.

${ }^{26}$ Ibid., 10.
} 
In the process framing "consequentialist" and "deontological" argumentation, we recognized that consequentialism and deontology are not exclusively separable and allow overlaps. Nootropics can be partly consequential (in seeing a continuity from a pill to a brain chip) and partly deontological (by assigning negative features of enhancers impacting on responsibilities and duties of specific professions, e.g., "pilot" or "surgeon"). Interestingly, the arguments do have a common ground based on utilitarianism: the idea that nootropics as a technology (in this case piracetam), is basically beneficial or detrimental for everyone. The reason why deontologists cannot avoid utilitarianism is due to principles of consequential and categorical morality that comes naturally to humans under various circumstances and conditions. ${ }^{27}$ Therefore, Greene suggests a "dualprocess theory of moral judgment" where deontological judgments are driven by our automatic emotional responses while utilitarian judgments are driven by more "controlled cognitive processes." ${ }^{28}$ Using functional magnetic resonance imaging ("fMRI") the author examined the cognitive abilities of human participants when presented with the famous "trolley problem" of moral philosophy. ${ }^{29}$ A majority of participants agreed to flip a switch to sacrifice one life for saving five. Interestingly, a majority disagreed in pushing a stranger onto the track to save five lives. According to the author, the emotional responses in pushing the stranger were relatively stronger than the impersonal and detached mode of flipping a switch. Although there can be an empirical explanation for the difference in judgments that people make when faced with such cases of moral dilemmas, and we may have reason to privilege one type of moral reasoning over the other, the principles and moral rules that play a role behind moral decision-making process are independent of the empirical evidence.

\section{Four principles in medical ethics}

Principlism takes into consideration four principles from divergent ideological positions: autonomy, beneficence, non-maleficence, and justice. ${ }^{30}$ The principle of autonomy allows the patient to exercise independent decision-making. Beneficence and non-maleficence stem from a caring entity that would minimize harm and maximize benefit to the patient. Justice from a societal level indicates all goods distributed according to just principles.

\footnotetext{
${ }^{27}$ Steven Pinker, The Blank Slate (New York: Viking, 2002).

${ }^{28}$ Joshua D. Greene, "Dual-Process Morality and the Personal/Impersonal Distinction: A Reply to McGuire, Langdon, Coltheart, And Mackenzie,” Journal of Experimental Social Psychology 45, no. 3 (2009): 581-584, doi:10.1016/j.jesp.2009.01.003.

29 Joshua D. Greene, “An Fmri Investigation of Emotional Engagement In Moral Judgment," Science 293, no. 5537 (2001): 2105-2108, doi:10.1126/science.1062872.

30 Tom L. Beauchamp and James F. Childress, Principles of Biomedical Ethics, 6th ed. (Oxford/New York: Oxford University Press, 2009).
} 
Informed consent is highlighted in Belmont Report and in case "inadequately informed... is detrimental to your autonomy," then informed consent is essential to autonomy. ${ }^{31}$ Outside the context of clinical care and medical research, systems of informed consent are hijacked by advertising of media that are designed primarily to sell products and encourage consumption. Much off-label uses of nootropic products have their health claims communicated through unregulated media such as social websites, blogs or forums. Nootropics piracetam amongst others has questionable dosing instructions that can prove to be harmful to its user. $^{32}$

Ethics authors point out the risks involved while assessing the beneficence and non-maleficence of nootropics. Stirling mentions that it is not always possible to know the likelihood of an event (uncertainty), nor is it possible to know what kind of event may happen (ambiguity), which leads us to not being aware of our lack of knowledge (ignorance). ${ }^{33}$ Therefore, the author argues that it is not only the risk that matters but uncertainty, ambiguity, and ignorance also play a major role in the decision-making process. Although Synofzik advises assessing the benefit-harm of a particular drug, the "data about benefit-harm ratios are still largely missing... questionable benefit-harm ratios of psychotropics are often not published, not adequately interpreted or falsely presented in directconsumer advertisements. ${ }^{\prime 34}$ Altogether, we overlook uncertainties, ambiguities, and ignorance of nootropics as well as dodge the question of potential benefitharm from the beginning on, which ultimately influences consideration of beneficence and non-maleficence.

Distributive justice is the equal distribution of resources that is thought to equalize gain. According to the encyclopedia of philosophy, it is "the allocation of the benefits and burdens of economic activity." ${ }^{35}$ Considering nootropics, non-allocation issues are important due to their "complex and dynamic relationship between the brain (and its related systems) and social interaction." 36

\footnotetext{
${ }^{31}$ Lars Øystein Ursin, "Personal Autonomy and Informed Consent," Medicine, Health Care and Philosophy 12, no. 1 (2008): 17-24, doi:10.1007/s11019-008-9144-0.

32 ImmInst Forums Reply. Subject: "New Energy Drink Contains Piracetam - Brain Health,” Longecity, 2008, http://www.longecity.org/forum/topic/22668-new-energy-drink-contains-piracetam/.

33 Andrew Stirling, "The Politics of GM Food: Risk, Science and Public Trust," 1999, http://users.sussex.ac.uk/ prfh0/adams_et_al_briefing_on_uncertainty.pdf.

${ }^{34}$ Matthis Synofzik, "Ethically Justified, Clinically Applicable Criteria for Physician DecisionMaking in Psychopharmacological Enhancement," Neuroethics 2, no. 2 (2009): 89-102, doi:10.1007/s12152-008-9029-1.

35 "Distributive Justice", in Stanford Encyclopedia of Philosophy, Fall 2008 Edition, Stanford.Library.Sydney.Edu.Au, 1996， https://stanford.library.sydney.edu.au/archives/fall2008/ entries/justice-distributive/.

36 Jean Decety and Julian Paul Keenan, "Social Neuroscience: A New Journal," Social Neuroscience 1, no. 1 (2006): 1-4, doi:10.1080/17470910600683549.
} 
If a nootropic causes positive impact on memory, it may, however, negatively influence interpersonal communication and trust relations. No evidence supports the idea that equal allocation of nootropics to all citizens will be beneficial, thus suggesting insufficient distributive justice as a value principle for nootropic use. Instead of only limiting ourselves to questions like "what impact it would have on our brain?" or "what society would become of it?" we also need to explore the socio-technical mediation of social relations and the potential gap between haves and have-nots.

\section{Virtue ethics}

If nootropics cause the agent to be unable to determine how she or he is making choices, whether her decisions are based on being cognitively enhanced or not, then that enhancement capability has surpassed its bounds. Especially in serious professions that deal with life and death (e.g. surgeon) it is important that nootropics retain the agent's ability to make a virtuous choice free of her or his enhancement, and only then can it be deemed permissible. Being virtuous means having a substantial amount of sound judgment and sentiments to make a stable and reliable decision while considering all plausible things associated with that decision. Nootropics are unlikely to mimic the aspects of a virtuous life because virtue is a developing experience that one needs to acquire and exercise in order to lead a good life. Cognitive enhancers generally provide strategies that depict only a narrow idea of what well-being and a good life represent. Therefore, nootropics should be considered facilitators rather than replacers of virtue and we need to learn to use nootropics virtuously.

\section{CONCLUSION}

The fate of nootropic concept depends on scientific advancement and its interaction with society and culture. Similar to the birth of nootropics, scientists can possibly make a costly failure to a serendipitous discovery by being openminded to unexpected results. However, diffused from the true definition coined by Giurgea, piracetam-like nootropics may carry substantial unknown risks to the healthy individuals. In any case, medicalization cannot be the only solution to human problems as the dimension do not touch mere humane approaches such as altruism or qualities like inspiration, humor, love, commitment, and devotion. Focusing only on cognitive enhancement may have its drawback of losing connection towards oneself and to the others, thus appreciating less of life and creativity. Although we are not at the stage where a drug translates our cognitive abilities beyond normal capacity, it is necessary that we set up a systematic framework based on a consensus paradigm to best accommodate future situations with beneficence and non-maleficence. 
In the review, we have seen polar opposite views advocating and opposing cognitive enhancement. It is clear from the overview that empirical evidence to support nootropics among healthy and ill individuals is inconclusive. Therefore, before ethical claims or policies are made, robust empirical research should be conducted to find out its executive functions as well as how it alters human virtues including empathy and motivation. Individuals with enhanced cognitive abilities do not necessarily have a happier, healthier life. As an example, transgenic mice with enhanced memory due to a mutation has enhanced the capacity to experience and remember pain because of the same mutation. ${ }^{37}$ Given the fact that authenticity and personhood of a bio-psychosocial human encompass more than any measured performance, nootropic should, therefore, tap into the realm of cognitive enhancement with extra caution.

\section{BIBLIOGRAPHY}

Arnsten, Amy F. T., and Anne G. Dudley. "Methylphenidate Improves Prefrontal Cortical Cognitive Function Through A2 Adrenoceptor and Dopamine D1 Receptor Actions: Relevance to Therapeutic Effects in Attention Deficit Hyperactivity Disorder." Behavioral and Brain Functions 1, no. 1 (2005): 2. doi:10.1186/1744-9081-1-2.

Babcock, Quinton, and Tom Byrne. "Student Perceptions of Methylphenidate Abuse at a Public Liberal Arts College." Journal of American College Health 49, no. 3 (2000): 143-145. doi:10.1080/07448480009596296.

Beauchamp, Tom L., and James F. Childress. Principles of Biomedical Ethics. 6th ed. Oxford/New York: Oxford University Press, 2009.

Bostrom, Nick, and Anders Sandberg. "Cognitive Enhancement: Methods, Ethics, Regulatory Challenges." Science and Engineering Ethics 15, no. 3 (2009): 311-341. doi:10.1007/s11948009-9142-5.

Butcher, James. "Cognitive Enhancement Raises Ethical Concerns.” The Lancet 362, no. 9378 (2003): 132-133. doi:10.1016/s0140-6736(03)13897-4.

Cakic, Vince. "Smart Drugs for Cognitive Enhancement: Ethical and Pragmatic Considerations in the Era of Cosmetic Neurology." Journal of Medical Ethics 35, no. 10 (2009): 611-615. doi:10.1136/jme.2009.030882.

Chatterjee, Anjan. "Cosmetic Neurology: The Controversy over Enhancing Movement, Mentation, and Mood." Neurology 63, no. 6 (2004): 968-974. doi:10.1212/01.wnl.0000138438.88589.7c.

- "The Promise and Predicament of Cosmetic Neurology." Journal of Medical Ethics 32, no. 2 (2006): 110-113. doi:10.1136/jme.2005.013599.

- "Is It Acceptable for People to Take Methylphenidate to Enhance Performance? No." BMJ 338, no. 182 (2009): b1956. doi:10.1136/bmj.b1956.

De Smedt, Tim, Robrecht Raedt, Kristl Vonck, and Paul Boon. "Levetiracetam: Part II, The Clinical Profile of a Novel Anticonvulsant Drug." CNS Drug Reviews 13, no. 1 (2007): 57-78. doi:10.1111/j.1527-3458.2007.00005.x.

Decety, Jean, and Julian Paul Keenan. "Social Neuroscience: A New Journal." Social Neuroscience 1, no. 1 (2006): 1-4. doi:10.1080/17470910600683549.

37 Feng Wei et al., "Genetic Enhancement of Inflammatory Pain by Forebrain NR2B Overexpression,” Nature Neuroscience 4, no. 2 (2001): 164-169, doi:10.1038/83993. 
Dimond, Stuart J., and E. Y. M. Brouwers. "Increase in the Power of Human Memory in Normal Man Through the Use of Drugs." Psychopharmacology 49, no. 3 (1976): 307-309. doi:10.1007/bf00426834.

"Distributive Justice". Stanford Encyclopedia of Philosophy. Fall 2008 Edition. Stanford.Library.Sydney.Edu.Au, 1996. https://stanford.library.sydney.edu.au/archives/fall2008/ entries/justice-distributive/.

Farah, Martha J. "Emerging Ethical Issues in Neuroscience." Nature Neuroscience 5, no. 11 (2002): 1123-1129. doi:10.1038/nn1102-1123.

Farah, Martha J., Judy Illes, Robert Cook-Deegan, Howard Gardner, Eric Kandel, Patricia King, Eric Parens, Barbara Sahakian, and Paul Root Wolpe. "Neurocognitive Enhancement: What Can We Do and What Should We Do?" Nature Reviews Neuroscience 5, no. 5 (2004): 421-425. doi:10.1038/nrn1390.

French, Jacqueline A., Chiara Costantini, A. Brodsky, and Phillipp von Rosenstiel. "Adjunctive Brivaracetam for Refractory Partial-Onset Seizures: a Randomized, Controlled Trial." Neurology 75, no. 6 (2010): 519-525. doi:10.1212/wnl.0b013e3181ec7f7f.

Fukuyama, Francis. Our Posthuman Future: Consequences of the Biotechnology Revolution. 1st ed. Reprint, New York: Picador, 2003.

Giurgea, Corneliu, and Maurice Salama. "Nootropic Drugs." Progress in NeuroPsychopharmacology 1, no. 3-4 (1977): 235-247. doi:10.1016/0364-7722(77)90046-7.

Greely, Henry, Barbara Sahakian, John Harris, Ronald C. Kessler, Michael Gazzaniga, Philip Campbell, and Martha J. Farah. "Towards Responsible Use of Cognitive-Enhancing Drugs by the Healthy." Nature 456, no. 7223 (2008): 702-705. doi:10.1038/456702a.

Greene, Joshua D. “An Fmri Investigation of Emotional Engagement in Moral Judgment." Science 293, no. 5537 (2001): 2105-2108. doi:10.1126/science.1062872.

- "Dual-Process Morality and the Personal/Impersonal Distinction: A Reply to Mcguire, Langdon, Coltheart, And Mackenzie." Journal of Experimental Social Psychology 45, no. 3 (2009): 581-584. doi:10.1016/j.jesp.2009.01.003.

Gouliaev, Alex Haahr, and Alexander Senning. "Piracetam and Other Structurally Related Nootropics." Brain Research Reviews 19, no. 2 (1994): 180-222. doi:10.1016/01650173(94)90011-6.

Harris, John. "Is It Acceptable for People to Take Methylphenidate to Enhance Performance? Yes.” BMJ 338, no. 182 (2009): b1955. doi:10.1136/bmj.b1955.

ImmInst Forums Reply. Subject: "New Energy Drink Contains Piracetam - Brain Health," Longecity, 2008. http://www.longecity.org/forum/topic/22668-new-energy-drink-containspiracetam/.

Kayser, Bengt, Alexandre Mauron, and Andy Miah. "Current Anti-Doping Policy: A Critical Appraisal." BMC Medical Ethics 8, no. 1 (2007). doi:10.1186/1472-6939-8-2.

Le Strange, Richard. A History of Herbal Plants. Reprint, London: Angus \& Robertson Publ., 1977.

Margineanu, Doru Georg. "A Weird Concept with Unusual Fate: Nootropic Drug," Revue des Questions Scientifiques. Vol. 182 (1) (2011): 33- 52.

McCabe, Sean Esteban, John R. Knight, Christian J. Teter, and Henry Wechsler. "Non-Medical Use Of Prescription Stimulants Among US College Students: Prevalence and Correlates From a National Survey." Addiction 100, no. 1 (2005): 96-106. doi:10.1111/j.13600443.2005.00944.x.

Pinker, Steven. The Blank Slate. New York: Viking, 2002.

Racine, Eric, and Cynthia Forlini. "Cognitive Enhancement, Lifestyle Choice or Misuse of Prescription Drugs?”. Neuroethics 3, no. 1 (2008): 1-4. doi:10.1007/s12152-008-9023-7.

Stirling, Andrew. "The Politics of GM Food: Risk, Science and Public Trust," 1999. http://users.sussex.ac.uk/ prfh0/adams_et_al_briefing_on_uncertainty.pdf. 
Swierstra, Tsjalling, and Arie Rip. "Nano-Ethics as NEST-Ethics: Patterns of Moral Argumentation about New and Emerging Science and Technology." Nanoethics 1, no. 1 (2007): 3-20. doi:10.1007/s11569-007-0005-8.

Synofzik, Matthis. "Ethically Justified, Clinically Applicable Criteria for Physician DecisionMaking In Psychopharmacological Enhancement." Neuroethics 2, no. 2 (2009): 89-102. doi:10.1007/s12152-008-9029-1.

Turner, Danielle C., Trevor W. Robbins, Luke Clark, Adam R. Aron, Jonathan Dowson, and Barbara J. Sahakian. "Cognitive Enhancing Effects of Modafinil in Healthy Volunteers." Psychopharmacology 165, no. 3 (2003): 260-269. doi:10.1007/s00213-002-1250-8.

Ursin, Lars Øystein. "Personal Autonomy and Informed Consent." Medicine, Health Care and Philosophy 12, no. 1 (2008): 17-24. doi:10.1007/s11019-008-9144-0.

Wei, Feng, Guo-Du Wang, Geoffrey A. Kerchner, Susan J. Kim, Hai-Ming Xu, Zhou-Feng Chen, and Min Zhuo. "Genetic Enhancement of Inflammatory Pain by Forebrain NR2B Overexpression.” Nature Neuroscience 4, no. 2 (2001): 164-169. doi:10.1038/83993.

Winblad, Bengt. "Piracetam: A Review of Pharmacological Properties and Clinical Uses." CNS Drug Reviews 11, no. 2 (2006): 169-182. doi:10.1111/j.1527-3458.2005.tb00268.x.

Wolpe, Paul Root. "Treatment, Enhancement, and the Ethics Of Neurotherapeutics." Brain and Cognition 50, no. 3 (2002): 387-395. doi:10.1016/s0278-2626(02)00534-1. 